\title{
Quantitative analysis of irrigation water productivity in the middle reaches of Heihe River Basin, Northwest China
}

\author{
Donghao $\mathrm{Li}^{1}$, Taisheng $\mathrm{Du}^{1 *}$, Yue Cao ${ }^{1}$, Manoj Kumar Shukla², Di Wu${ }^{1}$, Xiuwei Guo ${ }^{1}$, Shichao Chen ${ }^{1}$ \\ (1. Center for Agricultural Water Research in China, China Agricultural University, Beijing 100083, China; \\ 2. Department of Plant and Environmental Sciences, New Mexico State University, NM 88003, USA)
}

\begin{abstract}
With the growing shortage of surface water resources, it is of great significance for improving the irrigation water productivity (IWP) to ensure the water and food security. The contribution of the driving factors of the IWP and the rational regulation of the input factors of agricultural production is required. In this paper, 118 and 80 sampling points were selected in Pingchuan and Liaoquan irrigation districts (PLID, the spacing of sampling point is approximately $1 \mathrm{~km}$ ) and the middle reaches of the Heihe River basin (MHRB, the spacing of sampling point is approximately $10 \mathrm{~km}$ ), respectively. Soil characteristics and management measures near the sampling points were obtained. Results showed that the average value of the IWP in MHRB was $1.67 \mathrm{~kg} / \mathrm{m}^{3}$, with a moderate heterogeneity in the space. The main driving factors of IWP were irrigation, fertilization and planting density. On the PLID, the contribution rates of soil factors and management measures to IWP were $20.6 \%$ and $35.2 \%$, respectively, and the contribution of soil factors to IWP increased to $43.8 \%$ in the MHRB, while the contribution rate of management measures decreased to $24.8 \%$. It shows that in a small irrigation districts, from the perspective of farmers, the improvement of IWP should be mainly controlled by management measures, while in the large area of watershed scale, the spatial differences in soil factors also need to be considered by the government management departments, when they want to increase IWP through regulating management measures.
\end{abstract}

Keywords: irrigation water productivity, driving factors, quantitative analysis, partial least squares, maize DOI: $10.25165 /$ j.ijabe.20191205.4759

Citation: Li D H, Du T S, Cao Y, Shukla M K, Wu D, Guo X W, et al. Quantitative analysis of irrigation water productivity in the middle reaches of Heihe River Basin, Northwest China. Int J Agric \& Biol Eng, 2019; 12(5): 119-125.

\section{Introduction}

Water is an important natural resource, and with population and industry growth, the gap between water supply and demand will also grow ${ }^{[1]}$. By 2050 , the pressure on water resource will increase more than $20 \%$ over the current level ${ }^{[2]}$. In addition, with the development of human society, the world population will increase to approximately 9.15 billion by 2050 , which will lead to increasing demand for food ${ }^{[3]}$. At present, agriculture is a major sector for the water use, consuming about $70 \%$ of total water use in the world ${ }^{[4]}$; however, shortages of water resource will limit the high crop yields ${ }^{[5]}$. Therefore, improving agricultural water productivity is an important measure for ensuring global water safety and food security in the future.

Increasing water productivity relieves pressure on water

\section{Received date: 2018-11-06 Accepted date: 2019-09-14}

Biographies: Donghao Li, $\mathrm{PhD}$, research interests: Agricultural water saving theory and new technology, Email: donghaolea@qq.com; Yue Cao, master, research interests: Agricultural water saving theory and new technology, Email: 602761678@qq.com; Manoj Kumar Shukla, PhD, Professor, research interests: Saturated heterogeneous soil water and salt transport, Email: shuklamk@ nmsu.edu; Di Wu, PhD candidate, research interests: Agricultural water saving theory and new technology, Email: 302608467@qq.com; Xiuwei Guo, PhD candidate, research interests: Agricultural water saving theory and new technology, Email: 1059397292@qq.com; Shichao Chen, PhD candidate, research interests: Agricultural water saving theory and new technology, Email: 1257146326@qq.com;

*Corresponding author: Taisheng $\mathrm{Du}, \mathrm{PhD}$, Professor, research interests: Agricultural water saving theory and regulation technology for improving crop water use efficiency, China Agricultural University, No.17, Qinghua East Road, Beijing 100083, China. Tel: +86-10-62738398, Fax: +86-10-62738398, Email: dutaisheng@cau.edu.cn. resources $^{[6]}$. The concept of water productivity is not the same in different fields and at different research scales ${ }^{[7-11]}$. Based on "More Crop per Drop", Molden ${ }^{[12]}$ proposed the irrigation water productivity (IWP) concept and defined it as the crop yield per irrigation water amount. IWP reflects the production efficiency of unit water in agricultural production and is an important indicator for evaluating irrigation management and irrigation systems. Therefore, increasing IWP has great importance to the development and sustainability of food production and irrigated agriculture.

IWP reflects the relationship between crop yield and irrigation water use. Crop yield is closely related to the growth and development, and the transfer of water resources from source to crop involves canal water transport, soil infiltration, root absorption and so on. Therefore, the IWP is affected by factors which affect crop yield and irrigation water applied. The main factors affecting yield and irrigation amount are variety, climate, soil, and management ${ }^{[9,13,14]}$. Research has shown that IWP is influenced by genetic factors, and the difference in the eco-physiological characteristics of different varieties of crops affects the yield formation and water consumption ${ }^{[15]}$. In addition, the formation of crop yields is closely related to the air temperature, solar radiation and precipitation ${ }^{[16,17]}$. Recent evidence suggests that under rainfed conditions the potential yield of maize and potato could decline by $19 \%$ and $50 \%$, respectively, by the middle of this century, due to the gradual increase of global average temperature ${ }^{[18]}$.

Water and mineral elements essential for crop growth come from the soil. Previous studies have reported that the physical and chemical characteristics of different types of soil vary greatly, and crops have different absorption and utilization of water and nutrients in the soil ${ }^{[19,20]}$. However, among all the factors 
affecting IWP, management measures are easily controlled (e.g., the application of water, fertilizers and pesticides, the input of man-machineries). Hatfield ${ }^{[21]}$ pointed out that water use efficiency (Ratio of yield to evapotranspiration, WUE $=\mathrm{Y} / \mathrm{ET}$ ) can be increased by $25 \%$ to $40 \%$ through soil management practices involving tillage. Compared with unfertilized treatment, applying $\mathrm{N}$ fertilizer can significantly increase water productivity ${ }^{[22]}$. In the Hexi Corridor region of arid northwestern China, $\mathrm{Li}^{[23]}$ analyzed agricultural production statistics for the past 30 years and found that agronomic practice factors (irrigation, fertilization, agricultural film and agricultural pesticide) had greater impacts on IWP than climate factors (daily mean temperature, solar radiation and precipitation).

Factors controlling IWP need to be regulated to obtain the best crop yield and minimize water input. At present, many studies are focused on the influence of a certain factor on IWP, and there are few studies on the effects of driving factors on IWP under the multi-factor synergies. The middle of Heihe River Basin (MHRB) is an important production area of seed maize in Northwest China. In this area, the crop varieties and climatic factors have little effect on spatial differences in IWP because the variety of maize planted was relatively single and the spatial difference of climate factors was small. Therefore, our quantitative analysis of IWP was mainly focused on soil and management factors, and the main objectives of this study are to: a) understand the spatial difference of IWP, soil factors and management measures; b) analyze the key driving factors of IWP in soil factors and management measures; c) quantify the contribution of various factors to IWP.

\section{Materials and methods}

\subsection{Study area}

The middle reach of Heihe river basin, located in the middle of Qilian mountains and Badain Jaran desert $\left(38^{\circ} 36^{\prime}-39^{\circ} 45^{\prime} \mathrm{N}\right.$, $99^{\circ} 16^{\prime}-100^{\circ} 40^{\prime} \mathrm{E}$, average altitude is $1470.5 \mathrm{~m}$ ), includes Ganzhou district, Linze county and Gaotai county of Zhangye city, Gansu Province. The catchment area is $11300 \mathrm{~km}^{2}$, with average annual rainfall of $69-216 \mathrm{~mm}$ mainly concentrated in the June to September crop growth period, average annual evaporation of 1453-2351 mm, and continental arid climate ${ }^{[24]}$. The Pingchuan and Liaoquan irrigation district (PLID), which is located in the north of Linze county $\left(39^{\circ} 17^{\prime}-39^{\circ} 24^{\prime} \mathrm{N}, 99^{\circ} 56^{\prime}-100^{\circ} 10^{\prime} \mathrm{E}\right)$, the average altitude is $1373 \mathrm{~m}$ and the irrigation area is $1100 \mathrm{~km}^{2}$, with the annual average precipitation of $117 \mathrm{~mm}$, and the annual potential evaporation of $2365.6 \mathrm{~mm}$.

\subsection{Field investigation and sampling design}

In 2015 , a grid of $1 \mathrm{~km} \times 1 \mathrm{~km}$ was used to design 118 sampling points (the spacing of sampling point is approximately $1 \mathrm{~km}$ ) in PLID, and a grid of $5 \mathrm{~km} \times 10 \mathrm{~km}$ was used to design 80 sampling points (the spacing of sampling point is approximately $10 \mathrm{~km}$ ) throughout the MHRB in 2016, and the crop planted in the sampling field was maize. GPS was used to record the latitude, longitude and elevation of the sampling points (Figure 1).

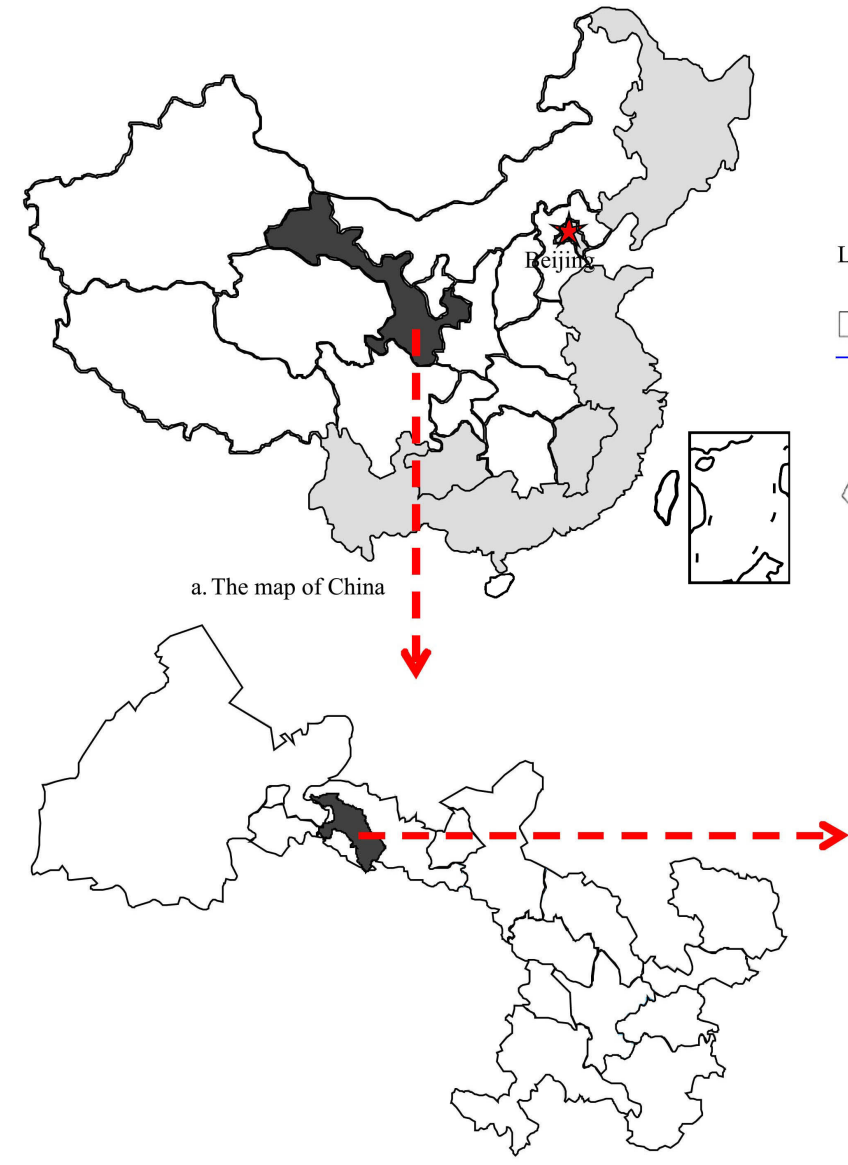

b. The map of Gansu province

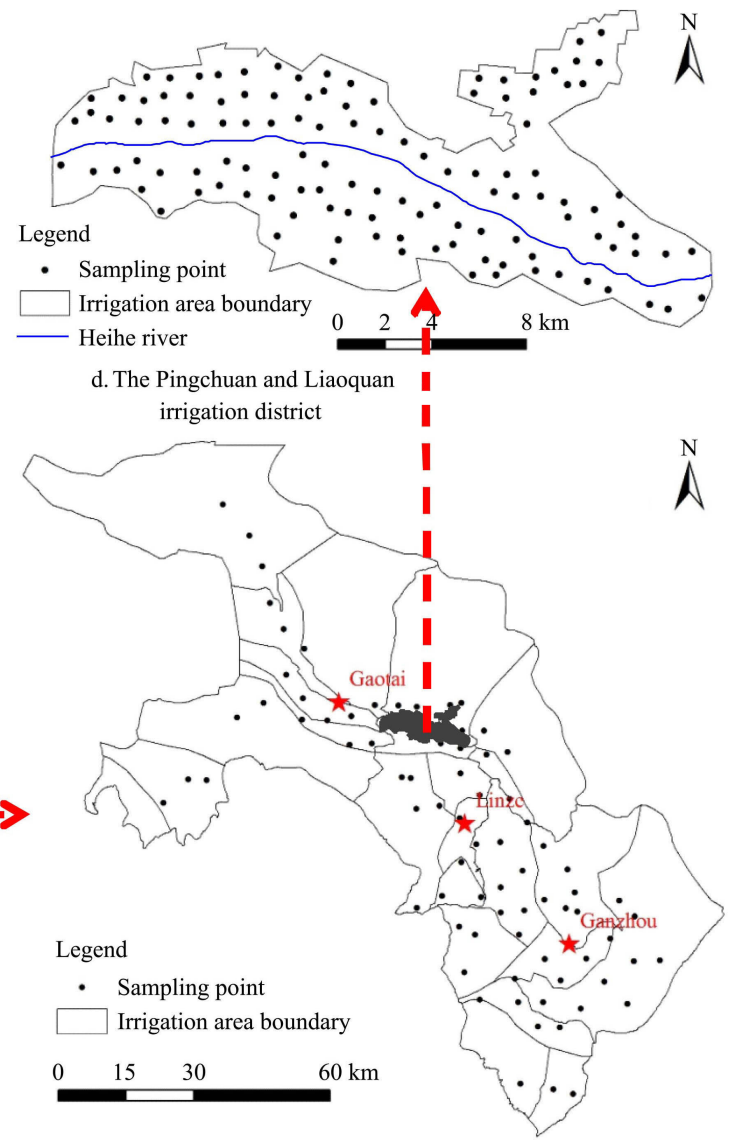

c. The middle of Heihe River basin

Figure 1 Location of study area and the sampling point distribution

\subsubsection{Soil factors}

Before the maize was planted (early April), composite soil samples (in a $10 \mathrm{~m} \times 10 \mathrm{~m}$ plot) with three replications were collected from the cultivated $(0-30 \mathrm{~cm})$ and bottom layer (30-
$100 \mathrm{~cm})$. Simultaneously, two soil samples were collected near the sampling points by cutting rings (with the diameter of $5 \mathrm{~cm}$ and volume of $100 \mathrm{~cm}^{3}$ ) for measurements of soil bulk density (BD) and gravimetric soil water content (SWC). After the soil samples 
were air-dried in the laboratory, the air-dried soil samples were divided into two subsamples. One was sieved through a $2 \mathrm{~mm}$ mesh for particle-size analysis by laser diffraction using a laser particle size analyzer (Mastersizer 2000 analyzer, UK); the other was passed through a $0.25 \mathrm{~mm}$ mesh for soil chemical properties measurements. The soil organic matter (SOM) was measured by the potassium dichromate oxidation method ${ }^{[25]}$. The soil total nitrogen (TN) was digested by $\mathrm{H}_{2} \mathrm{SO}_{4}$ and cupric sulfate-potassium sulfate $\left(\mathrm{CuSO}_{4}-\mathrm{K}_{2} \mathrm{SO}_{4}\right)$ as the catalyst agent and measured by the Kjeldahl method with an automatic Kjeldahl apparatus (FOSS 2300 Kjeltec Analyzer Unit, Sweden) ${ }^{[26]}$. The available nitrogen (AN) was measured using a continuous flow analyzer (Auto Analyzer 3, Bran+Luebbe, SEAL Analytical GmbH, Germany $)^{[27]}$. Available phosphorus (AP) was determined by the Olsen extraction method using alkaline sodium bicarbonate as the extractant in a 20:1 ratio ${ }^{[28]}$. The soil samples were calcined in a muffle furnace at $450^{\circ} \mathrm{C}$ for $3 \mathrm{~h}$ and then hydrochloric acid $(3.5 \mathrm{~mol} / \mathrm{L})$ was added, after that shaken for 16 hours to convert the soil organic phosphorus into inorganic phosphorus, and total phosphorus (TP) was measured by Olsen extraction method ${ }^{[29]}$.

\subsubsection{Management factors}

In August of each year, the irrigation water amount was obtained from Water Conservancy Bureau of Zhangye City (automatic monitoring by triangular weir flowmeter) and the fertilizer application was carried out in our study area through a survey. At the maturity stage of maize, the planting row and spacing were measured to obtain planting density, and at the same time, the grain yield was measured in $100 \mathrm{~m}^{2}$ area at each sampling location. A 100-seed sample was selected randomly, weighed, and further dried for $72 \mathrm{~h}$ at $80^{\circ} \mathrm{C}$ to determine the seed moisture. Finally, every sampling crop yields have been converted into the grain weight $(Y)$ with $13 \%$ moisture content ${ }^{[30]}$ using the seed moisture data. In this paper, the IWP is defined as the yield per unit of irrigation water use, which was calculated as follows:

$$
I W P=Y / I W
$$

where, $I W P$ is irrigation water productivity, $\mathrm{kg} / \mathrm{m}^{3} ; Y$ is grain yield, $\mathrm{kg} / \mathrm{hm}^{2} ; I$ is the amount of irrigation water, $\mathrm{m}^{3} / \mathrm{hm}^{2}$. Therefore, the experimental data in our study includes one dependent variable factor (IWP) and 18 independent variables. The 18 independent variables and their abbreviations are shown in Table 1.

Table 1 Independent variable factors and their abbreviation

\begin{tabular}{lc}
\hline \multicolumn{1}{c}{ Full name } & Abbreviation \\
\hline Initial soil organic matter & SOM \\
Initial total nitrogen & TN \\
Initial available nitrogen & AN \\
Initial total phosphorus & TP \\
Initial available phosphorus & AP \\
Soil bulk density & BD \\
Soil water content & SWC \\
Soil clay content of $0-30 \mathrm{~cm}$ & Clay0 \\
Soil silt content of $0-30 \mathrm{~cm}$ & Silt0 \\
Soil sand content of $0-30 \mathrm{~cm}$ & Sand0 \\
Soil clay content of $30-100 \mathrm{~cm}$ & Clay1 \\
Soil silt content of $30-100 \mathrm{~cm}$ & Silt1 \\
Soil sand content of $30-100 \mathrm{~cm}$ & Sand1 \\
Irrigation water & IW \\
Amount of nitrogen fertilizer applied & NF \\
Amount of phosphorus fertilizer applied & PF \\
The total amount of fertilizer applied & TF \\
Planting density & PD \\
\hline
\end{tabular}

\subsubsection{Contribution rate analysis of independent variables}

There is a significant correlation between soil characteristics and related factors ${ }^{[31]}$, so there may be a problem of collinearity between the independent variables when analyzing the influence of independent variables such as, soil factors and management measures on IWP. And to solve this problem, partial least-squares (PLS) regression can be used to quantitatively analyze the dependent variable of $\operatorname{IWP}^{[32-34]}$. The variable projection importance (VIP) means the importance of the independent variable $X_{j}$ in explaining partial variable $Y$ in PLS regression analysis $^{[35]}$, and which was defined as follows:

$$
V I P_{j}=\sqrt{\frac{p}{R d\left(Y ; t_{1}, \mathrm{~L}, t_{m}\right)} \sum_{h=1}^{m} R d\left(Y ; t_{h}\right) w_{h j}^{2}}
$$

where, $W_{h j}$ is the $j$-th component of axis $W_{h}$; and $X_{j}$ interprets $Y$ by passing $t_{h}$.

When all the VIP values are 1, it implies that the independent variable $X_{j}$ has the same effect (importance and influence) on the dependent variable. When VIP $>1$, it means that the independent variable has more important. When VIP $<0.8$, it means that the independent variable contributes less to the dependent variable ${ }^{[35-37]}$ Therefore, we can calculate the contribution of each independent variable to the dependent variable by the complex correlation coefficient between the VIP value of the independent variable and the PLS regression model ${ }^{[38]}$ as follows:

$$
W_{i}=\frac{V I P_{i}}{\sum_{i=1}^{n} V I P_{i}} R \times 100 \%
$$

where, $W_{i}$ is the contribution of the $i$-th factor to the dependent variable; VIP $i$ is the VIP value of the $i$-th factor; $R$ is the complex correlation coefficient of the PLS regression model, and $n$ is the number of independent variables in the PLS model.

In this paper, the correlation of IWP and its driving factors were analyzed by SPSS 21.0 software. Partial least squares regression was analyzed by XLSTAT 2010 software. We also used EXCEL 2010 for the descriptive statistics and drawing the figure.

\section{Results and discussion}

\subsection{Descriptive statistical analysis}

The Kolmogorov-Smirnov (K-S) test is widely used in applied statistical studies $^{[39,40]}$. From the descriptive statistics of IWP and its driving factors (Table 2), the results of K-S test showed that the data of IWP and most of the driving factors were consistent with a normal distribution. On the scale of PLID, the average value of IWP was $1.48 \mathrm{~kg} / \mathrm{cm}^{3}$ and the coefficient of variation (CV) was $40 \%$, showed a moderate heterogeneity in space ${ }^{[41]}$. However, the average value of IWP in MHRB was $1.67 \mathrm{~kg} / \mathrm{cm}^{3}$, and it also exhibits moderate heterogeneity $(\mathrm{CV}=39 \%)$ in space. $\mathrm{Wu}^{[42]}$ showed that per cubic water can produce $2.0 \mathrm{~kg}$ of grain in developed areas of water-saving agriculture. The mean of IWP between oasis region of northwest China and some developed countries or regions is still having a gap. Therefore, there is a potential for increasing the IWP in the Oasis region of northwest China.

It can be found from Table 2, the $\mathrm{CV}$ value of the independent variables except $\mathrm{BD}$ varies between $12 \%$ and $71 \%$, and showing moderate degree of spatial heterogeneity at different scales. The $\mathrm{CV}$ values of $\mathrm{BD}$ were $6 \%$ and $7 \%$ on the PLID and MHRB, respectively, showing a weak heterogeneity in space. Thus, there were spatial differences in soil environmental factors and 
management measures. In addition, with the increase of sampling distance, the $\mathrm{CV}$ values of soil factors also increased in addition to SOM and Sand1 (soil sand content of 30-100 cm). Di Virgilio et al. studied spatial variability of switchgrass in $4.8 \mathrm{hm}^{2}$ fields (the sampling was about $90 \mathrm{~m}$ ), and reported that the $\mathrm{CV}$ values of SOM, TN, AP, Clay, Silt, Sand, SWC were 15\%, 11\%, 27\%, 10.4\%, $13.7 \%, 19.1 \%, 16 \%$, respectively ${ }^{[43]}$. Therefore, we were found that the spatial differences in soil properties will increase with the increase of sampling distance. There is no clear trend between the spatial difference of management measures and the sampling distance. From the data of fertilization (Table 2), it can be seen that the amount of nitrogen fertilizer applied in the MHRB was far beyond the level of the annual nitrogen application of 46$200 \mathrm{~kg} / \mathrm{hm}^{2}$ in the cultivated land ${ }^{[44]}$. However, the content of TN was $0.85 \mathrm{~g} / \mathrm{kg}$ in MHRB, indicating that the local soil nitrogen was at a medium level ${ }^{[45]}$, and the aforementioned results indicate that there may be severe nitrogen leaching in the oasis region of northwest China.

Table 2 Descriptive statistics of irrigation water productivity and its driving factors

\begin{tabular}{|c|c|c|c|c|c|c|c|c|}
\hline \multirow{2}{*}{ Variable } & \multicolumn{4}{|c|}{ PLID scale } & \multicolumn{4}{|c|}{ MHRB scale } \\
\hline & Mean & Std. & $\mathrm{CV}$ & $\mathrm{K}-\mathrm{S}$ & Mean & Std. & $\mathrm{CV}$ & K-S \\
\hline $\mathrm{IWP} / \mathrm{kg} \cdot \mathrm{m}^{-3}$ & 1.48 & 0.60 & 40 & 0.25 & 1.67 & 0.64 & 39 & 0.59 \\
\hline $\mathrm{SOM} / \mathrm{g} \cdot \mathrm{kg}^{-1}$ & 13.58 & 4.08 & 30 & 0.83 & 14.83 & 3.21 & 22 & 0.82 \\
\hline $\mathrm{TN} / \mathrm{g} \cdot \mathrm{kg}^{-1}$ & 0.85 & 0.27 & 32 & 0.40 & 0.85 & 0.31 & 37 & 0.99 \\
\hline $\mathrm{AN} / \mathrm{mg} \cdot \mathrm{kg}^{-1}$ & 52.34 & 21.74 & 42 & 0.00 & 37.55 & 26.61 & 71 & 0.00 \\
\hline $\mathrm{TP} / \mathrm{g} \cdot \mathrm{kg}^{-1}$ & 0.72 & 0.11 & 15 & 0.79 & 0.52 & 0.11 & 22 & 0.99 \\
\hline $\mathrm{AP} / \mathrm{mg} \cdot \mathrm{kg}^{-1}$ & 27.77 & 15.82 & 57 & 0.85 & 15.25 & 7.78 & 51 & 0.43 \\
\hline $\mathrm{BD} / \mathrm{g} \cdot \mathrm{cm}^{-3}$ & 1.58 & 0.10 & 6 & 0.61 & 1.57 & 0.11 & 7 & 0.98 \\
\hline $\mathrm{SWC} / \%$ & 15.5 & 4.28 & 28 & 0.12 & 14.7 & 4.63 & 31 & 0.71 \\
\hline Clay $0 / \%$ & 12.4 & 2.15 & 17 & 0.03 & 10.3 & 2.29 & 22 & 0.83 \\
\hline Silt0/\% & 48.7 & 8.94 & 18 & 0.44 & 49.7 & 12.92 & 26 & 0.69 \\
\hline Sand $0 / \%$ & 38.9 & 10.85 & 28 & 0.28 & 40.0 & 14.82 & 37 & 0.47 \\
\hline Clay $1 / \%$ & 15.2 & 4.82 & 32 & 0.16 & 9.9 & 3.40 & 34 & 0.95 \\
\hline Silt1/\% & 53.6 & 14.22 & 27 & 0.00 & 48.9 & 15.36 & 31 & 0.26 \\
\hline Sand $1 / \%$ & 31.2 & 18.46 & 59 & 0.01 & 41.2 & 18.37 & 45 & 0.32 \\
\hline $\mathrm{IW} / 10^{3} \mathrm{~m}^{3} \cdot \mathrm{hm}^{-2}$ & 7.25 & 1.00 & 14 & 0.39 & 7.33 & 1.30 & 18 & 0.01 \\
\hline $\mathrm{NF} / \mathrm{kg} \cdot \mathrm{hm}^{-2}$ & 601 & 263.51 & 44 & 0.48 & 470 & 63.17 & 13 & 0.12 \\
\hline $\mathrm{PF} / \mathrm{kg} \cdot \mathrm{hm}^{-2}$ & 86 & 38.63 & 45 & 0.09 & 108 & 28.36 & 26 & 0.09 \\
\hline $\mathrm{TF} / \mathrm{kg} \cdot \mathrm{hm}^{-2}$ & 724 & 253.97 & 35 & 0.54 & 612 & 74.31 & 12 & 0.04 \\
\hline $\mathrm{PD} /$ plant $\cdot \mathrm{m}^{-1}$ & 8.75 & 1.38 & 16 & 0.02 & 9.62 & 1.71 & 18 & 0.32 \\
\hline
\end{tabular}

Note: PLID: The typical irrigation district, MHRB: Middle reaches of the Heihe River basin, Mean: The mean value, Std: Standard deviation, CV: Coefficient of variation, K-S: Asymp. Sig. (2-tailed), IWP: irrigation water productivity, SOM: Initial soil organic matter, TN: Initial total nitrogen, $\mathrm{AN}$ : Initial available nitrogen, TP: Initial total phosphorus, AP: Initial available phosphorus, BD: bulk density, SWC: soil water content, Clay0: Soil clay content of 0-30 cm, Silt0: soil silt content of 0-30 cm, Sand0: soil sand content of 0-30 cm, Clay1: Soil clay content of $30-100 \mathrm{~cm}$, Silt1: Soil silt content of $30-100 \mathrm{~cm}$, Sand1: Soil sand content of 30-100 cm, IW: Irrigation water, NF: Amount of nitrogen fertilizer applied, PF: Amount of phosphorus fertilizer applied, TF: The total amount of fertilizer applied, PD: Planting density.

\subsection{Reasonable sampling number analysis}

In the analysis of soil spatial characteristics on a large scale, it is of great significance to determine the reasonable number of samples for improving work efficiency and reducing costs ${ }^{[46,47]}$. The analysis of reasonable sampling numbers was mainly based on the Cochran formula ${ }^{[48]}$. After more than 40 years of application and improvement, the calculation formula for the reasonable sampling number of random variables in the region was defined as follows ${ }^{[49,50]}$.

$$
R S N=t^{2} \cdot C v^{2} / \Delta^{2}
$$

where, $R S N$ is the reasonable number of samples; $t$ is the $T$-test threshold for a random variable at a certain level; $C v$ is the coefficient of variation (the ratio of the standard deviation to the mean); and $\Delta$ is the relative error allowed.

When the level of confidence is $95 \%$, the reasonable sampling of the factors affecting the productivity of irrigation water in oasis farmland is shown in Table 3. The results show that the sampling number of all factors meets the requirements when the allowable error is $10 \%$, so the sampling data in this paper can represent the actual situation of the oasis farmland.

Table 3 Reasonable sampling number of IWP and its influencing factors in Heihe Oasis farmland

\begin{tabular}{|c|c|c|c|c|c|c|}
\hline \multirow{2}{*}{ Variable } & \multicolumn{3}{|c|}{ PLID Scale $(N=118)$} & \multicolumn{3}{|c|}{ MHRB Scale $(N=80)$} \\
\hline & $\Delta=5 \%$ & $\Delta=10 \%$ & $\Delta=15 \%$ & $\Delta=5 \%$ & $\Delta=10 \%$ & $\Delta=15 \%$ \\
\hline IWP & 254 & 64 & 29 & 243 & 61 & 27 \\
\hline SOM & 143 & 36 & 16 & 95 & 24 & 11 \\
\hline $\mathrm{TN}$ & 163 & 41 & 19 & 241 & 61 & 27 \\
\hline $\mathrm{AN}$ & 272 & 68 & 31 & 627 & 77 & 70 \\
\hline $\mathrm{TP}$ & 37 & 10 & 5 & 82 & 21 & 10 \\
\hline $\mathrm{AP}$ & 516 & 109 & 58 & 406 & 72 & 46 \\
\hline $\mathrm{BD}$ & 6 & 2 & 1 & 7 & 2 & 1 \\
\hline SWC & 122 & 31 & 14 & 162 & 41 & 18 \\
\hline Clay0 & 48 & 12 & 6 & 80 & 20 & 9 \\
\hline Silt0 & 54 & 14 & 6 & 103 & 26 & 14 \\
\hline Sand0 & 123 & 31 & 14 & 201 & 51 & 23 \\
\hline Clay1 & 161 & 41 & 19 & 213 & 54 & 24 \\
\hline Silt1 & 112 & 28 & 13 & 148 & 37 & 17 \\
\hline Sand1 & 349 & 108 & 61 & 335 & 74 & 38 \\
\hline IW & 30 & 8 & 4 & 47 & 12 & 6 \\
\hline $\mathrm{NF}$ & 305 & 77 & 34 & 35 & 9 & 4 \\
\hline $\mathrm{PF}$ & 333 & 84 & 37 & 98 & 25 & 11 \\
\hline $\mathrm{TF}$ & 196 & 49 & 22 & 27 & 7 & 3 \\
\hline PD & 39 & 10 & 5 & 49 & 13 & 6 \\
\hline
\end{tabular}

Note: PLID: The typical irrigation district, MHRB: Middle reaches of the Heihe River basin, $\Delta$ : the relative errors, IWP: irrigation water productivity, SOM: Initial soil organic matter, $\mathrm{TN}$ : Initial total nitrogen, $\mathrm{AN}$ : Initial available nitrogen, TP: Initial total phosphorus, AP: Initial available phosphorus, BD: bulk density, SWC: soil water content, Clay0: Soil clay content of 0-30 cm, Silt0: soil silt content of 0-30 cm, Sand0: soil sand content of 0-30 cm, Clay1: Soil clay content of 30-100 cm, Silt1: Soil silt content of 30-100 cm, Sand1: Soil sand content of 30-100 cm, IW: Irrigation water, NF: Amount of nitrogen fertilizer applied, PF: Amount of phosphorus fertilizer applied, TF: The total amount of fertilizer applied, PD: Planting density.

\subsection{Colinearity analysis of driving factors of IWP}

Although the selection of more independent variables can make the analysis more comprehensive, it also brings multiple collinearity problems. The 18 independent variables in this study can be classified into three categories: soil chemical properties, soil physical properties and crop management measures. There is a significant correlation between $\mathrm{SOM}$ and $\mathrm{TN}^{[51]}$, clay and silt $^{[52]}$. The common collinearity diagnostic criteria include conditional index (CI), tolerance (TOL) and variance inflation factor (VIF), in which TOL and VIF are reciprocal ${ }^{[53-55]}$. We used VIF to diagnose collinearity between independent variables. The small VIF values indicate low $R^{2}$, indicating that the collinearity between the independent variables is weak. In general, when the VIF value is less than 10 , it is shown that the collinearity problem 
between the independent variables does not exist or can be neglected ${ }^{[56]}$.

The collinearity diagnostic using VIF values of the factors affecting IWP are shown in Table 4. The VIF value of Sand0 (soil sand content of 0-30 cm) and Sand1 were far more than 10, and the VIF value of Clay1 (soil clay content of 30-100 cm) and Silt1 (soil silt content of $30-100 \mathrm{~cm}$ ) in the MHRB were 10.8 and 11.9 respectively. On the scale of the MHRB, the VIF values of irrigation water (IW), amount of nitrogen fertilizer applied (NF), amount of phosphorus fertilizer applied (PF) and total amount of fertilizer applied (TF) were all more than 10, which were 14.3, 46.7, 25.4, 51.3, respectively. The results indicate that there was collinearity between the physical properties of the soil (sand, silt and clay), irrigation and fertilization (NF, PF and TF). Belsley ${ }^{[57]}$ pointed out that when quantifying the dependent variable, the collinearity problem would mask the true relationship between variables, and making it difficult to distinguish the individual effects of each independent variable. Therefore, in the quantitative analysis of IWP, we adopted the PLS regression analysis method, which can solve the collinearity problem.

Table 4 Collinearity diagnosis independent variables (VIF)

\begin{tabular}{|c|c|c|}
\hline Variable & PLID scale & MHRB scale \\
\hline $\mathrm{SOM} / \mathrm{g} \cdot \mathrm{kg}^{-1}$ & 6.4 & 3.9 \\
\hline $\mathrm{TN} / \mathrm{g} \cdot \mathrm{kg}^{-1}$ & 6.6 & 4.1 \\
\hline $\mathrm{AN} / \mathrm{mg} \cdot \mathrm{kg}^{-1}$ & 1.4 & 1.5 \\
\hline $\mathrm{TP} / \mathrm{g} \cdot \mathrm{kg}^{-1}$ & 1.6 & 5.2 \\
\hline $\mathrm{AP} / \mathrm{mg} \cdot \mathrm{kg}^{-1}$ & 2.0 & 3.8 \\
\hline $\mathrm{BD} / \mathrm{g} \cdot \mathrm{cm}^{-3}$ & 1.7 & 2.2 \\
\hline $\mathrm{SWC} / \%$ & 1.8 & 2.0 \\
\hline Clay $0 / \%$ & 5.2 & 5.8 \\
\hline Silt0/\% & 6.6 & 7.6 \\
\hline Sand $0 / \%$ & $\infty$ & $\infty$ \\
\hline Clay $1 / \%$ & 3.9 & 10.8 \\
\hline Silt1/\% & 4.1 & 11.9 \\
\hline Sand $1 / \%$ & $\infty$ & $\infty$ \\
\hline $\mathrm{IW} / 10^{3} \mathrm{~m}^{3} \cdot \mathrm{hm}^{-2}$ & 1.5 & 14.3 \\
\hline $\mathrm{NF} / \mathrm{kg} \cdot \mathrm{hm}^{-2}$ & 14.8 & 46.7 \\
\hline $\mathrm{PF} / \mathrm{kg} \cdot \mathrm{hm}^{-2}$ & 2.1 & 25.4 \\
\hline $\mathrm{TF} / \mathrm{kg} \cdot \mathrm{hm}^{-2}$ & 15.7 & 51.3 \\
\hline $\mathrm{PD} /$ plant $\cdot \mathrm{m}^{-1}$ & 1.2 & 1.8 \\
\hline
\end{tabular}

Note: PLID: The typical irrigation district, MHRB: Middle reaches of the Heihe River basin, $\infty$ : The value of VIF $>10^{6}$, IWP: irrigation water productivity, SOM: Initial soil organic matter, $\mathrm{TN}$ : Initial total nitrogen, $\mathrm{AN}$ : Initial available nitrogen, TP: Initial total phosphorus, AP: Initial available phosphorus, BD: bulk density, SWC: soil water content, Clay0: Soil clay content of 0-30 cm, Silt0: soil silt content of 0-30 cm, Sand0: soil sand content of 0-30 cm, Clay1: Soil clay content of 30-100 cm, Silt1: Soil silt content of 30-100 cm, Sand1: Soil sand content of 30-100 cm, IW: Irrigation water, NF: Amount of nitrogen fertilizer applied, PF: Amount of phosphorus fertilizer applied, TF: The total amount of fertilizer applied, PD: Planting density.

\subsection{Analysis of driving factors of IWP}

In this study, 18 independent variables were analyzed by PLS regression, and the importance of variable projection importance index (VIP value) was used to quantitatively analyze the influence factors of IWP (Figure 2). The main driving factors of IWP (VIP $>0.8$ ) in PLID are IW, NF, PD (planting density), TF and AN. At the scale of MHRB, the main driving factors of IWP are IW, PF, $\mathrm{PD}$, Silt0 (soil silt content of 0-30 cm), Sand0 (soil sand content of 0-30 cm), AP, TN, SOM, Clay0 (soil clay content of 0-30 cm), NF and TP. The results showed that the IWP was mainly influenced by the management measures at PLID scale, and the IWP on the scale of MHRB was mainly influenced by management measures and soil factors, and the main reason was that the difference in spatial distribution of soil factors increases with the increase of sampling distance (Table 2) ${ }^{[43]}$. In addition, Li et al. ${ }^{[23]}$ also pointed out that in irrigated agriculture, management measures were the main factors restricting the increase of IWP.

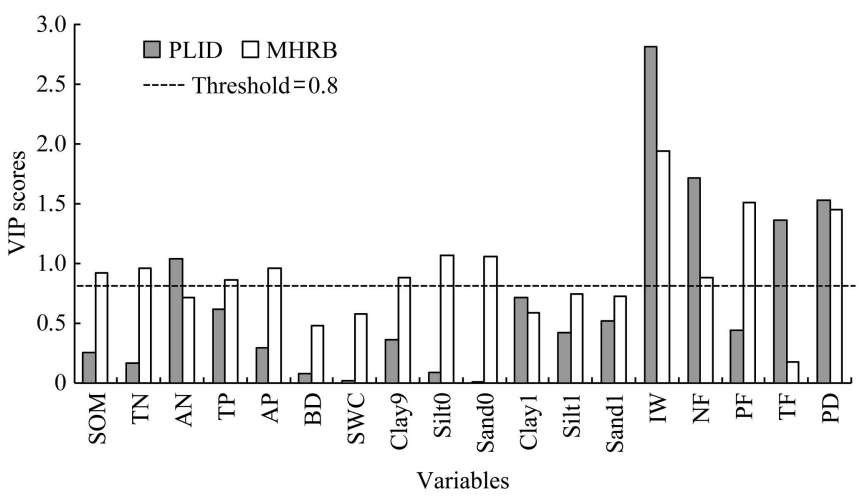

Figure 2 Variable projection importance of driving factors for irrigation water productivity

In most arid areas, water has replaced arable farmland as a key factor in restricting agricultural production ${ }^{[58]}$. It can be found from the VIP score chart of the driving factors of IWP (Figure 2) that the VIP score of IW was greater than other factors under different regions, which indicated that the contribution of IW to the IWP was much more than other factors in the arid oasis region of northwest China. In addition, the PD of maize also has a large VIP score at different scales, mainly because the PD has a significant positive correlation with the yield of maize, and the appropriate increase in PD has a significant effect on the increase of crop yield ${ }^{[59,60]}$.

\subsection{Contribution rate of driving factors of IWP}

Under different sampling distance, the influence of the driving factors on IWP changed (Figure 2). Quantifying the contribution rate of each driving factor to IWP, analyzing its characteristics with the change of the sampling distance, and adjusting the input of soil and agronomic measures in agricultural production, can effectively improve the IWP and could ensure the food security in arid oasis region.

In China, irrigated farmland accounts for $49 \%$ of the total arable land, and produces $75 \%$ of the country's grain yield and more than $90 \%$ of the economic crop yield ${ }^{[61]}$. This study found that the contribution of IW to IWP was the largest in PLID and MHRB scales, $12.6 \%$ and $8.1 \%$ respectively (Figure 3), mainly because irrigation was the main factor to ensure grain production ${ }^{[4]}$. According to the results, the second largest contributor to IWP in PLID scale was NF (7.7\%), while in the MHRB scale, the second largest contributor to IWP was PF $(6.3 \%)$. The main reason was that the application of nitrogen and phosphate fertilizer can indirectly affect water use efficiency through the physiological regulation of crops $^{[21]}$. In addition, the differences in the contribution rates of $\mathrm{N}$ and $\mathrm{P}$ fertilizers to IWP were mainly due to: 1) there were differences in the mean value of soil nitrogen and phosphorus content; and 2) the average amount of $\mathrm{N}$ on the scale of PLID was much higher than that of the MHRB, while the application of $\mathrm{P}$ was just the opposite. A study has shown that suitable PD can effectively improve the water productivity of maize ${ }^{[62,63]}$. As can be seen from Figure 3, the PD has the third-highest contribution to IWP at different sampling distance, 
and the contribution rate was $6.8 \%$ and $6 \%$ respectively. In summary, the main driving factors of IWP are irrigation, fertilization and planting density.

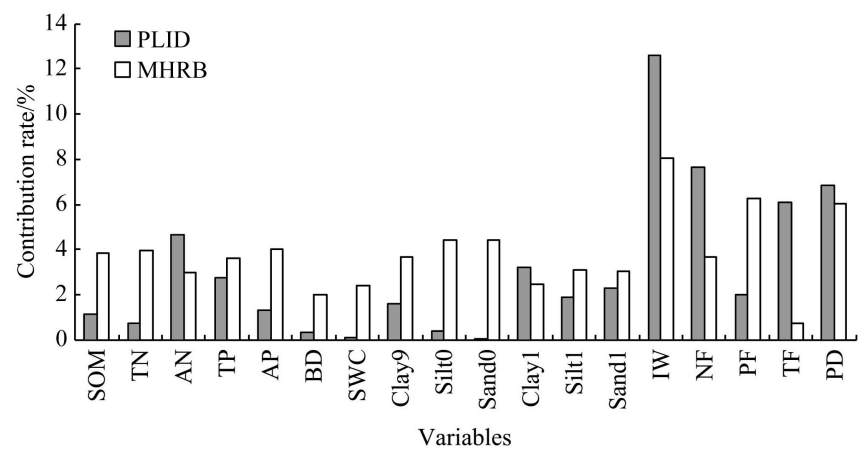

Figure 3 Contribution rate of driving factors of irrigation water productivity

Analysis of the contribution rate of soil factors and management measures to IWP, improving the growth environment of crops have a significant effect on promoting IWP ${ }^{[9,13,14]}$. In this study, the soil factors mainly include soil physics (soil texture, SWC, BD) and soil chemistry (SOM, soil nitrogen, and phosphorus content), and the management measures were IW, fertilization and PD. The contribution of different types of driving factors to IWP is shown in Figure 4. Other factors mainly refer to crop varieties, climatic conditions, and soil factors (soil heavy metal and trace element content, $\mathrm{PH}$, conductivity, etc.) not covered in this paper, and agronomic practices (farming methods, cover conditions, pesticide application, etc.). The contribution rates of soil factors and management measures to IWP were $20.6 \%$ and $35.2 \%$, respectively on the PLID scale, and the contribution of soil factors to IWP increased to $43.8 \%$ in the MHRB, while the contribution rate of management measures decreased to $24.8 \%$. It shows that in a small irrigation districts, from the perspective of farmers, the improvement of IWP should be mainly controlled by management measures, while in the large area of watershed scale, the spatial differences in soil factors also need to be considered by the government management departments, when they want to increase IWP through regulating management measures.

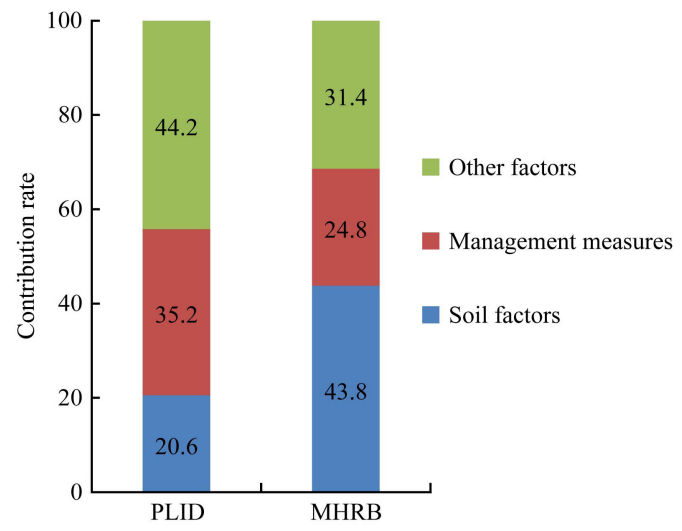

Figure 4 Contribution of different types of driving factors to irrigation water productivity

\section{Conclusions}

The average value of the IWP of maize in the middle reaches of Heihe River in northwestern China was $1.67 \mathrm{~kg} / \mathrm{m}^{3}$. The IWP has a moderate degree of heterogeneity $(\mathrm{CV}=40 \%)$ in the space, and has a larger space for improvement in the study areas. The amount of nitrogen fertilizer used in the study area was large. The collinearity diagnosis of the influencing factors of IWP showed that the soil factors and management measures will interact with each other and showed strong collinearity. The quantitative analysis of IWP through the PLS-VIP method showed that the contribution rates of soil factors and management measures to IWP were $20.6 \%$ and $35.2 \%$, respectively on the PLID scale, and the contribution of soil factors to IWP increased to $43.8 \%$ in the MHRB scale, while the contribution rate of management measures decreased to $24.8 \%$. Based on the results of PLID and MHRB scales, the main driving factors of IWP were irrigation, fertilization and planting density.

\section{Acknowledgements}

We are grateful for the research grants from the National Natural Science Foundation of China (Grant No. 51725904, 51790534, 51621061, 91425302), the national Key Research program (2016YFC0400207), and the Discipline Innovative Engineering Plan (111 Program, B14002).

\section{[References]}

[1] Sun S, Zhang C, Li X, Zhou T, Wang Y, Wu P, Cai H. Sensitivity of crop water productivity to the variation of agricultural and climatic factors: A study of Hetao irrigation district, China. Journal of Cleaner Production, 2017; 142: 2562-2569.

[2] Rosegrant M W, Ringler C, Zhu T. Water for agriculture: maintaining food security under growing scarcity. Annual review of Environment and Resources, 2009; 34: 205-222.

[3] Carr T, Yang H, Ray C. Temporal variations of water productivity in irrigated corn: An analysis of factors influencing yield and water use across central Nebraska. PloS one, 2016; 11(8): e0161944.

[4] Kang S, Hao X, Du T, Tong L, Su X, Lu H, Li X, Huo Z, Li S, Ding R. Improving agricultural water productivity to ensure food security in China under changing environment: From research to practice. Agricultural Water Management, 2017; 179: 5-17.

[5] Müller T, Bouleau C R, Perona P. Optimizing drip irrigation for eggplant crops in semi-arid zones using evolving thresholds. Agricultural Water Management, 2016; 177: 54-65.

[6] Liu H, Zhao W. Advances in researches of agriculture water productivity. Advances in Earth Science, 2007; 22(1): 58-65.

[7] Bouman B. A conceptual framework for the improvement of crop wate productivity at different spatial scales. Agricultural Systems, 2007; 93(1): 43-60.

[8] Expósito A, Berbel J. Agricultural irrigation water use in a closed basin and the impacts on water productivity: The case of the Guadalquivir river basin (Southern Spain). Water, 2017; 9(2): 136.

[9] Molden D, Murray-Rust H, Sakthivadivel R, Makin I, A water-productivity framework for understanding and action//Kijne J W, Barker R, Molden D. Water Productivity in Agriculture: Limits and Opportunities for Improvement. Colombo: CABI Publishing, 2003.

[10] Passioura J. Increasing crop productivity when water is scarce-from breeding to field management. Agricultural Water Management, 2006; 80(1): 176-196.

[11] Molden D, Oweis T, Steduto P, Bindraban P, Hanjra M A, Kijne J. Improving agricultural water productivity: between optimism and caution. Agricultural Water Management, 2010; 97(4): 528-535.

[12] Molden D. Accounting for water use and productivity. International Water Management Institute, Colombo, Srilanka, 1997.

[13] Ali M H, Talukder $M$. Increasing water productivity in crop production - a synthesis. Agricultural Water management, 2008; 95(11): 1201-1213.

[14] Zwart S J, Bastiaanssen W G. Review of measured crop water productivity values for irrigated wheat, rice, cotton and maize. Agricultural Water Management, 2004; 69(2): 115-133.

[15] Sun C, Dong W, Liu M, Dong B. Research progression on water use efficiency and its difference mechanism of different crop varieties. Chinese Agricultural Science Bulletin, 2009; 25(12): 117-121.

[16] Carter E K, Melkonian J, Steinschneider S, Riha S J. Rainfed maize yield response to management and climate covariability at large spatial scales. Agricultural \& Forest Meteorology, 2018; S256-257: 242-252.

[17] Chen C, Baethgen W E, Robertson A. Contributions of individual 
variation in temperature, solar radiation;and precipitation to crop yield in the North China Plain, 1961-2003. Climatic Change, 2013; 116(3-4): 767-788.

[18] Resop J P, Fleisher D H, Timlin D J, Mutiibwa D, Reddy V R. Climate, water management, and land use: Estimating potential potato and corn production in the US northeastern seaboard region. Transactions of the ASABE, 2016; 59(6): 1539-1553.

[19] Kurwakumire N, Chikowo R, Mtambanengwe F, Mapfumo P, Snapp S, Johnston A, Zingore S. Maize productivity and nutrient and water use efficiencies across soil fertility domains on smallholder farms in Zimbabwe. Field Crops Research, 2014; 164: 136-147.

[20] Tolk J A, Howell T A. Sunflower water productivity in four Great Plains soils. Field Crops research, 2012; 127: 120-128.

[21] Hatfield J L, Sauer T J, Prueger J H. Managing soils to achieve greater water use efficiency. Agronomy Journal, 2001; 93(2): 271-280.

[22] Liu Z, Chen Z, Ma P, Meng Y, Zhou J. Effects of tillage, mulching and N management on yield, water productivity, $\mathrm{N}$ uptake and residual soil nitrate in a long-term wheat-summer maize cropping system. Field Crops Research, 2017; 213: 154-164.

[23] Li X, Zhang X, Niu J, Tong L, Kang S, Du T, Li S, Ding R. Irrigation water productivity is more influenced by agronomic practice factors than by climatic factors in Hexi Corridor, Northwest China. Scientific Reports, 2016; doi: 10.1038/srep37971.

[24] Nian Y, Li X, Zhou J, Hu X. Impact of land use change on water resource allocation in the middle reaches of the Heihe River Basin in northwestern China. Journal of Arid Land, 2014; 6(3): 273-286.

[25] Liu G, Jiang N, Zhang L, Liu Z. Soil physical and chemical analysis and description of soil profiles. Standards Press of China, Beijing, 1996

[26] Lin C, Zhu T, Liu L, Wang D. Influences of major nutrient elements on $\mathrm{Pb}$ accumulation of two crops from a $\mathrm{Pb}$-contaminated soil. Journal of Hazardous Materials, 2010; 174(1-3): 202-208.

[27] Kamphake L J, Hannah S A, Cohen J M. Automated analysis for nitrate by hydrazine reduction. Water Research, 1967; 1(3): 205-216.

[28] Liang Y, Xie X, Xu G, Zhao C, Zhang L. Studied on proper wavelength and linear range in the colorimetry of phospho-molybdenumblue. Environmental Monitoring in China, 2007; 23(1): 35-37.

[29] Olsen S R. Estimation of available phosphorus in soils by extraction with sodium bicarbonate. U.S. Department of Agriculture. Circular 939, 1954

[30] Li D, Shao M. Soil organic carbon and influencing factors in different landscapes in an arid region of northwestern China. Catena, 2014; 116: 95-104.

[31] Heuscher S A, Brandt C C, Jardine P M. Using soil physical and chemical properties to estimate bulk density. Soil Science Society of America Journal, 2005; 69(1): 51-56.

[32] Wold S, Sjöström M, Eriksson L. PLS-regression: a basic tool of chemometrics. Chemometrics and Intelligent Laboratory Systems, 2001; 58(2): 109-130.

[33] Shi Z H, Ai L, Li X, Huang X D, Wu G L, Liao W. Partial least-squares regression for linking land-cover patterns to soil erosion and sediment yield in watersheds. Journal of Hydrology, 2013; 498: 165-176.

[34] Galindo Prieto B, Eriksson L, Trygg J. Variable influence on projection (VIP) for orthogonal projections to latent structures (OPLS). Journal of Chemometrics, 2014; 28(8): 623-632.

[35] Wang H. Partial least-squares regression method and applications. National Defense Idustry Press, Beijing, 1999.

[36] Leggett M, Diaz-Zorita M, Koivunen M, Bowman R, Pesek R, Stevenson CLeister T. Soybean response to inoculation with Bradyrhizobium japonicum in the United States and Argentina. Agronomy Journal, 2017; 109(3): 1031-1038.

[37] Wold S. PLS for multivariate linear modeling. Chemometric Methods in Molecular Design, 1995; 2: 195.

[38] Hua L. Soil erosion dynamics induced by natural and anthropogenic forcings and its regionalization application: A case study in Hubei Province, China, Huazhong Agricultural University, Wuhan, China, 2013.

[39] Makarov A A, Simonova G I. Some properties of two-sample kolmogorov-smirnov test in the case of contamination of one of the samples. Journal of Mathematical Sciences, 2016; 1-6.

[40] Banerjee B, Pradhan B. Kolmogorov-smirnov test for life test data with hybrid censoring. Communication in Statistics: Theory and Methods,
2018; 47(11): 2590-2604

[41] Li T, Hao X, Kang S. Spatiotemporal Variability of Soil Moisture as Affected by Soil Properties during Irrigation Cycles. Soil Science Society of America Journal, 2014; 78(2): 598.

[42] Wu P, Zhao X, Feng H, Wang Y. Agricultural Economic Rational Water Consumption and Strategy Analysis for Water Saving Potential in China. Journal of Agricultural Science and Technology, 2007; 9(6): 13-17.

[43] Di Virgilio N, Monti A, Venturi G. Spatial variability of switchgrass (Panicum virgatum L.) yield as related to soil parameters in a small field. Field Crops Research, 2007; 101(2): 232-239.

[44] Cameron K C, Di H J, Moir J L. Nitrogen losses from the soil/plant system: a review. Annals of Applied Biology, 2013; 162(2): 145-173.

[45] National S C O. Chinese soil. China Agriculture Press, Beijing, 1998

[46] Yim M H, Joo S J, Shutou K, Nakane K. Spatial variability of soil respiration in a larch plantation: estimation of the number of sampling points required. Forest Ecology and Management, 2003; 175(1): $585-588$.

[47] Wang J M, Yang R X, Yu F. Spatial variability of reconstructed soil properties and the optimization of sampling number for reclaimed land monitoring in an opencast coal mine. Arabian Journal of Geosciences, 2017; 10(2): 46.

[48] Cochran W G. Sampling Techniques. New York: John Wiley and Sons, 1977.

[49] Yang S X, Lei Z D. Spatial structure of soil water content and sampling number determination in the field. Acta Geographica Sinica, 1993; 5: $447-456$.

[50] Leopizzi S, Gondret K, Boivin P. Spatial variability and sampling requirements of the visual evaluation of soil structure in cropped fields. Geoderma, 2018; 314: 58-62.

[51] Hassink J. Effects of soil texture and grassland management on soil organic $\mathrm{C}$ and $\mathrm{N}$ and rates of $\mathrm{C}$ and $\mathrm{N}$ mineralization. Soil Biology and Biochemistry, 1994; 26(9): 1221-1231.

[52] Weil R R, Brady N C, Weil R R. The nature and properties of soils. Pearson, 2016.

[53] Midi H, Sarkar S K, Rana S. Collinearity diagnostics of binary logistic regression model. Journal of Interdisciplinary Mathematics, 2010; 13(3): 253-267.

[54] Chennamaneni P R, Echambadi R, Hess J D, Syam N. Diagnosing harmful collinearity in moderated regressions: A roadmap. International Journal of Research in Marketing, 2016; 33(1): 172-182.

[55] Huang C L, Jou Y, Cho H. A new multicollinearity diagnostic for generalized linear models. Journal of Applied Statistics, 2016; 43(11): 2029-2043.

[56] Marquaridt D W. Generalized inverses, ridge regression, biased linear estimation, and nonlinear estimation. Technometrics, 1970; 12(3): 591-612.

[57] Belsley D A, Kuh E, Welsch R E. Regression diagnostics: Identifying influential data and sources of collinearity, 571. John Wiley \& Sons, 2005.

[58] Oweis T Y, Improving agricultural water productivity: A viable response to water scarcity in the dry areas//Choukr-Allah R, Ragab R, Rodriguez-Clemente R. Integrated Water Resources Management in the Mediterranean Region: Dialogue Towards New Strategy. Berlin: Springer, 2012.

[59] Li D, Jiang X, Tong L. Effect of planting density on root-shoot growth and water utilization efficiency of seed corn. Journal of Drainage and Irrigation Machinery Engineering, 2014; 32(12): 1091-1097.

[60] Van Roekel R J, Coulter J A. Agronomic responses of corn to planting date and plant density. Agronomy Journal, 2011; 103(5): 1414-1422.

[61] Chen L. Vigorously strengthen irrigation and water conservancy to ensure national food security. Sichuan Water Resources, 2012; 2: 1-2.

[62] Jia Q, Sun L, Wang J, Li J, Ali S, Liu T, et al. Limited irrigation and planting densities for enhanced water productivity and economic returns under the ridge-furrow system in semi-arid regions of China. Field Crops Research, 2018; 221: 207-218.

[63] Okbagabir S G, Angiras N N, Ghebreslassie B M. Effect of moisture conservation methods and plant density on the productivity of two maize (Zea mays L.) varieties under semi-arid tropics of Hamelmalo, Eritrea. American Journal of Plant Sciences, 2016; 8(1): 28-39. 